\title{
Cartas ao Editor
}

\section{Letter to the Editor}

\section{Vacina antimeningocócica}

\author{
Antimeningococic vaccine
}

\section{Senhor Editor,}

Venho, por este meio, esclarecer um comentário feito pelos autores do artigo "Avaliação da proteção conferida pela vacina antimeningocócica BC no Estado de Santa Catarina, Brasil, 1990/92".

No artigo "Avaliação da proteção conferida pela vacina antimeningocócica no Estado de Santa Catarina, Brasil, 1990/92", publicado na Revista de Saúde Pública, 30 (5): 460-70, 1996, meu nome é citado como autor do documento "A vacina antimeningocócica BC de procedência cubana no Brasil".

Nesse documento procurei demonstrar que a determinação da eficácia por meio da situação vacinal e da cobertura vacinal* não era um método adequado pois os grupos vacinados e não vacinados não são comparáveis. A fórmula adotada por Orenstein é uma derivação da clássica fórmula de eficácia vacinal. Os valores encontrados para as meningites de diferentes etiologias, que se basearam nas informações fornecidas pelo Estado de Santa Catarina, revelaram uma "alta proteção" independentemente do agente etiológico responsável pelo quadro de meningite.

O autor do trabalho refere que essa "alta proteção contra meningites virais" era devido a um erro de classificação do estado vacinal (todo caso com vacinação incompleta ou ignorada foi digitado como não vacinada) e a apuração correta da situação vacinal eliminaria o óbice acima mencionado e permitiria determinar a real eficácia da vacina.

Com os dados da situação vacinal dos casos e da cobertura vacinal coletados pelo principal autor do trabalho, e constantes do documento citado no rodapé do artigo, recalculamos a eficácia e os resultados são mostrados abaixo:

\begin{tabular}{lc}
\hline Diagnóstico & Eficácia (\%) \\
\hline Doenças meningocócicas & 83 \\
Meningites bacterianas não especificadas & 86 \\
Meningites bacterianas especificadas & 86 \\
Meningites por hemófilo & 77 \\
Meningites virais & 65 \\
\hline
\end{tabular}

Desta forma a vacina antimeningocócica proporcionaria hipoteticamente um alto nível de proteção para todas as meningites de etiologia bacteriana. Estes resultados vêm ratificar que este método apresenta vieses na determinação da eficácia vacinal.

Como o estudo realizado não é um estudo controlado e se baseou em informações da situação vacinal dos casos e da cobertura vacinal registradas pela Secretaria de Saúde de Santa Catarina, para determinar e comparar a incidência da doença meningocócica nos grupos vacinado e não vacinado, seria interessante calcular a eficácia vacinal para meningites de outras etiologias e com as mesmas características de transmissão para servir de controle de algumas variáveis que possam interferir no resultado, como, por exemplo, um risco de transmissão maior no grupo não vacinado.

Uma comissão de epidemiologistas designada pelo Ministério da Saúde, chefiada pelo Prof. Dr. Maurício Barreto da Universidade Federal da Bahia, e a Organização Panamericana de Saúde recomendam a realização de um estudo controlado para conhecer eficácia desta vacina principalmente nas crianças menores de 5 anos.

\section{S. Paulo, fevereiro de 1997.} José Cássio de Moraes

Prof. Adjunto do Depto. de Medicina Social Faculdade de Ciências Médicas de São Paulo

*Orenstein, W. A.; Bernier, R. H.; Dondero, T. J.; Hinman, A. R.; Marks, J. S.; Bart, K. J.; Sirotkin, B. Field evaluation of vaccine efficacy Bulletin of World Health Organization, 63: (6): 1055-1068, 1985. 


\section{Senhor Editor,}

Em resposta à carta do Professor Moraes, gostaria de esclarecer alguns pontos:

1 - De fato, o Prof. Moraes, no trabalho citado no rodapé da pág. 461 da Revista de Saúde Pública (30: 460, 1996), calculou eficácias com um erro sistemático de classificação de estado vacinal, o que foi perfeitamente documentado. Na Nota Técnica - preliminar - também citada no mesmo rodapé, incluímos tabelas com levantamento corrigido, realizado pelo responsável pela vigilância das meningites de Santa Catarina (HM), a pedido do autor principal. Todavia ele nos enviou os dados agregados, sem discriminação de grupo etário, de modo que não era possível separar quais casos eram da coorte de vacinados. $\mathrm{O}$ título dessa tabela, da qual o Professor Moraes teria se utilizado para calcular as eficácias referidas em sua carta, diz: "Situação vacinal dos casos de meningite em menores de 11 anos nos municípios vacinados com a VA-mengoc BC em Santa Catarina, 90/ 92". Explicitando: o período de observação era de quase três anos e como o grupo etário alvo por ocasião da vacinação era de 3 meses a 7 anos, o levantamento para ser uniforme foi feito em todos os menores de 11 anos de cada ano do período. Essa tabela, obviamente, portanto, incluía crianças nascidas depois da campanha e os maiores de 7 anos do início da campanha. Conseqüentemente, não é correto estimar a eficácia com esses dados, pois os casos não se restringiam à coorte de vacinados e não vacinados. Esse procedimento errôneo levou a que o Professor Moraes obtivesse eficácias superestimadas. Aliás esses cálculos não deveriam ter sido realizados também, por que, como constantes da mesma tabela, nas meningites virais e nas outras especificadas (não meningocócicas) a proporção de estado vacinal ignorado era extremamente alta, 40\%, o dobro da doença meningocócica e das meningites não especificadas. O que, provavelmente, foi gerado pelo desinteresse de registrar o estado vacinal nas visitas domiciliares, quando de antemão sabia-se que não se tratava de caso de doença meningocócica. Para corrigir a informação vacinal no arquivo eletrônico dos casos de doença meningocócica, como pode ser visto no trabalho publicado (RSP, 30: 460, 1996), fomos, junto com o Dr. Klein, mais tarde, a Santa Catarina, fazer novo levantamento, e calculamos as estimativas de pessoas-ano a risco da coorte. Queremos registrar também que na tabela da Nota Técnica não há um item específico para meningite por hemófilo, razão pela qual não estamos totalmente seguros da origem dos dados da carta do Professor Moraes. Ainda que consideremos inapropriado, resolvemos, para atender ao Professor Moraes, calcular a "eficácia" da vacina contra a meningite por hemófilo, que teria, à semelhança da doença meningocócica, critérios diagnósticos melhor definidos, com os dados vacinais e da coorte corrigidos. Dependendo do critério de inclusão ou não de vacinas sem especificação de doses, encontramos os seguintes valores: para o grupo etário de 6 a 47 meses: $27 \%$ (i.c. $95 \%-97$ a $73 \%$ ) e $40 \%$ (i.c. $95 \%-66$ a $78 \%$ ) e, para o grupo de 6 a 89 meses: $15 \%$ (i.c. $95 \%-128$ a $68 \%$ ) e $37 \%$ (i.c. $95 \%$ : -74 a $77 \%$ ).

2 - O trabalho de Orenstein e outros do Bull. WHO $(23: 1055,1985)$ não trata especificamente da questão de comparabilidade de grupos vacinados e não vacinados em estudos de eficácia em meningites, nem a aplicabilidade da fórmula do da eficácia ( 1 - RR) tem a ver com isso. A questão é apenas de ajustamento pela inclusão de controles se houverem variáveis intervenientes significativas e importantes. A subclassificação por idade é, por exemplo, um desses procedimentos de controle. Acreditamos que o próprio texto da discussão do artigo que publicamos (em particular itens 4 e 5 às páginas 467-8) seja mais específico e responda ao questionamento.

3 - Não concordamos integralmente com a opinião de Barreto e outros sobre a conveniência de um estudo controlado (com alocação aleatória da vacina) no Brasil, pois, ainda que pareça óbvia, carece de realismo, se tornando puro cientificismo. Nós mesmos tentamos, antes da aplicação em massa dessa vacina no Brasil, fazer um estudo com essas características e não conseguimos. O rechaço vem do pessoal dos serviços de saúde pública, em função de questões éticas em vacinações contra uma enfermidade com tal gravidade e da existência de estudos anteriores encorajadores, como os de pré e pós-licenciamento em Cuba. Aliás, é conveniente que se faça um reparo à assertiva do Professor Moraes em relação às conclusões do grupo de trabalho: ele diz em sua carta que a comissão recomendou estudo controlado "principalmente nas crianças menores de 5 anos", o que não é correto (o grifo é nosso). A comissão afirma que considera satisfatória a evidência 
de eficácia dessa vacina em crianças de 4 anos e mais, o mesmo não acontecendo em menores de 4 anos. Discordando da opinião desse grupo de trabalho, em crianças de 2 a 3 anos consideramos, hoje, formalmente anti-ético um estudo controlado com placebo (a não ser que outra vacina antimeningocócica B, potencialmente melhor, seja usada como grupo de comparação). Nossa opinião parte da meta-análise dos três estudos do Brasil, (ver tabela 9, página 468 do artigo publicado na Revista de Saúde Pública, 30: 460, 1996), que dá estimativas de eficácia (1-OR\%) global de 56 a $62 \%$ e intervalos de confiança de +1 a $81 \%$ a +23 a $79 \%$, dependendo de escolhas sobre definição de casos. Intuitivamente, é óbvio, também, que a probabilidade de se obter ao acaso três amostras com eficácias de 40 a $70 \%$ é muito pequena. O que faltou para os estudos caso-controle realizados foi potência, em função de amostras pequenas, conseqüentes, aliás, à exclusão de casos não confirmados laboratorialmente e sem dados vacinais; o que, provavelmente, determinou, ainda, subestimativas da eficácia nesses grupos etários menores de 4 anos, em particular nos menores de 2 anos, nos quais a letalidade é maior (além do trabalho de referência, ver Costa, E. - Cadernos de Saúde Pública, 11 (2):
332, 1995 e International Journal of Epidemiology, 26 (3): 1997). Renovamos, portanto, a pergunta já feita em outra ocasião: Quem, numa epidemia de doença meningocócica B, com $20 \%$ de letalidade, deixaria de vacinar uma criança, mesmo que a proteção seja de apenas $50 \%$.

Por fim, aproveitamos a oportunidade para chamar a atenção para pequeno erro de edição da tabela 9 citada acima, pois na $2^{\text {a }}$ coluna (\% de aumento do poder bactericida), na linha de 24 a 47 meses, o valor de $64 \%$ deveria ser em itálico, demonstrando que é significativamente diferente de zero, como os demais valores da coluna. Escapou-nos também dois erros de concordância na revisão do texto, ambos na pág. 464: penúltima linha da $1^{\text {a }}$ coluna ("foi acrescentada" e não "foram acrescentados") e $4^{\text {a }}$ linha depois do subtítulo Estimativas Populacionais ("fornecem" e não "fornece").

Rio de Janeiro, 25 de março de 1997.

Eduardo de Azeredo Costa Departamento de Epidemiologia e Métodos Quantitativos da Escola Nacional de Saúde Pública 